\title{
Brr2p-mediated conformational rearrangements in the spliceosome during activation and substrate repositioning
}

\author{
Daniela Hahn, ${ }^{1}$ Grzegorz Kudla, ${ }^{2}$ David Tollervey, and Jean D. Beggs ${ }^{3}$ \\ Wellcome Trust Centre for Cell Biology, University of Edinburgh, Edinburgh EH9 3JR, United Kingdom
}

\begin{abstract}
Brr2p is one of eight RNA helicases involved in pre-mRNA splicing. Detailed understanding of the functions of Brr2p and other spliceosomal helicases has been limited by lack of knowledge of their in vivo substrates. To address this, sites of direct Brr2p-RNA interaction were identified by in vivo UV cross-linking in budding yeast. Cross-links identified in the U4 and U6 small nuclear RNAs (snRNAs) suggest U4/U6 stem I as a Brr2p substrate during spliceosome activation. Further Brr2p cross-links were identified in loop 1 of the U5 snRNA and near splice sites and 3' ends of introns, suggesting the possibility of a previously uncharacterized function for Brr2p in the catalytic center of the spliceosome. Consistent with this, mutant brr2-G858R reduced second-step splicing efficiency and enhanced cross-linking to $3^{\prime}$ ends of introns. Furthermore, RNA sequencing indicated preferential inhibition of splicing of introns with structured 3' ends. The Brr2-G858Rp cross-linking pattern in U6 was consistent with an open conformation for the catalytic center of the spliceosome during first-to-second-step transition. We propose a previously unsuspected function for Brr2p in driving conformational rearrangements that lead to competence for the second step of splicing.
\end{abstract}

[Keywords: splicing; RNA helicase; UV cross-linking; conformational state]

Supplemental material is available for this article.

Received June 24, 2012; revised version accepted September 13, 2012.

Pre-mRNA splicing proceeds via two trans-esterification reactions that are catalyzed by the spliceosome. The spliceosome is a multicomponent ribonucleoprotein (RNP) complex comprising the U1, U2, U4, U5, and U6 small nuclear RNAs (snRNAs) and their associated proteins as well as a multitude of non-snRNA-associated proteins (Will and Luehrmann 2011). Key to productive splicing is the establishment of a dynamic network of RNA-RNA interactions, including base-pairing between pre-mRNA and snRNAs and between different snRNAs (Valdakhan 2007). These interactions are highly dynamic and are thought to be dependent on the activities of $\mathrm{DExD} / \mathrm{H}$-box RNA helicases. RNA helicases use the energy derived from NTP hydrolysis to elicit conformational changes, including nucleic acid strand separation and/or protein displacement (Cordin et al. 2012). Although the activities of eight spliceosomal RNA helicases have been function-

Present addresses: ${ }^{1}$ Max F. Perutz Laboratories, Medical University of Vienna, A-1030 Vienna, Austria; ${ }^{2}$ MRC Human Genetics Unit, MRC Institute of Genetics and Molecular Medicine, University of Edinburgh, Edinburgh EH4 2XU, U.K.

${ }^{3}$ Corresponding author

E-mail j.beggs@ed.ac.uk

Article is online at http://www.genesdev.org/cgi/doi/10.1101/gad.199307.112. Freely available online through the Genes \& Development Open Access option. ally linked to distinct stages of the splicing cycle (Cordin et al. 2012), it has proved difficult to unambiguously assign specific RNA or RNP remodeling events to the activities of individual DExD/H-box proteins.

Brr2p is the only Ski2-like RNA helicase in the spliceosome and is thought to have more than one role in splicing (Small et al. 2006). Several lines of evidence indicate that Brr2p dissociates the U4/U6 snRNA duplex during spliceosome activation (Laggerbauer et al. 1998; Raghunathan and Guthrie 1998; Kuhn et al. 1999). However, the U4/U6 snRNA duplex contains two intermolecular helices (stems I and II) (Brow and Guthrie 1988), and it remains unclear whether Brr2p disrupts both stems and, if so, in which order. Brr2p is an integral component of the U5 snRNP and remains associated with the spliceosome throughout the catalytic phase (Lauber et al. 1996; Noble and Guthrie 1996; Bessonov et al. 2008). Splicing involves two trans-esterification reactions, and the catalytic center of the spliceosome must be remodeled between the two reactions to reposition the first-step products as secondstep substrates (Smith et al. 2008). Subsequent to the second trans-esterification reaction, the spliced mRNA is released and the spliceosome is disassembled in an ATPdependent manner. Brr2p activity is proposed to contribute to disassembly, as brr2 mutants cause an intron-release defect (Small et al. 2006). In this context, it was hypoth- 
esized that Brr2p might disrupt base-pairing between the $\mathrm{U} 2$ and U6 snRNAs.

Brr2p features an unusual architecture comprising two helicase $(\mathrm{H})$ and two Sec63 domains (Fig. 1A). Structural modeling predicts that pairs of helicase and Sec63 domains form functional units, suggesting that Brr2p consists of a unique $\mathrm{N}$-terminal domain and two consecutive helicase cassettes (Pena et al. 2009; Zhang et al. 2009).

A

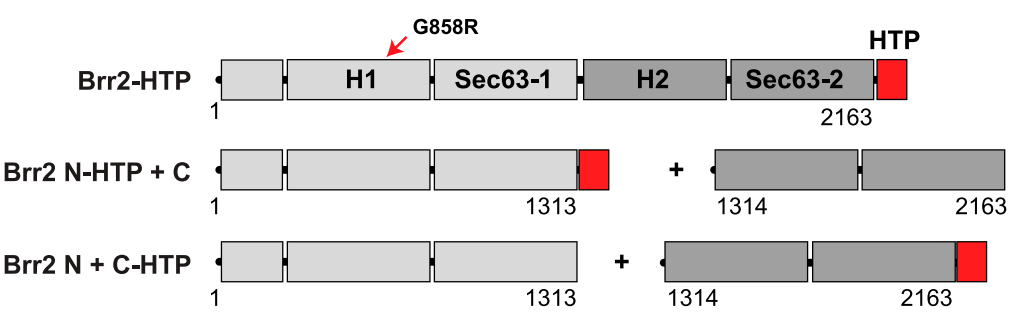

B

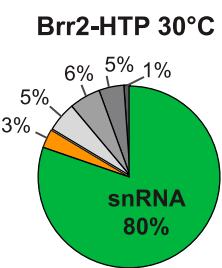

[9.8 million]

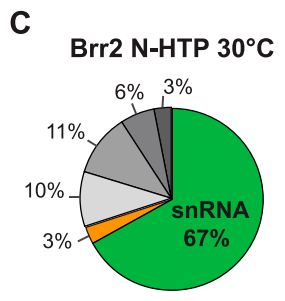

[7.5 million]

D

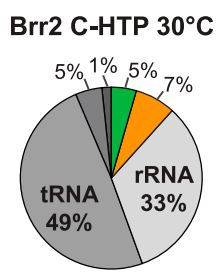

[193]
E no $\operatorname{tag} 30^{\circ} \mathrm{C}$

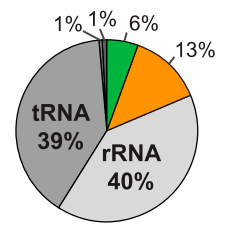

[159]

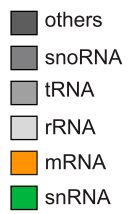

[ ] mapped reads
F

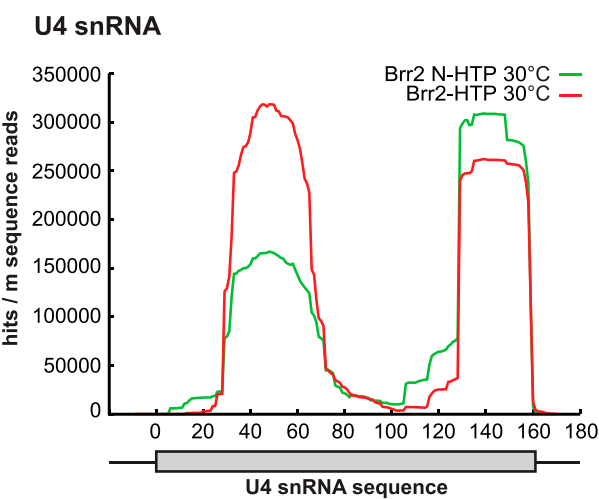

H

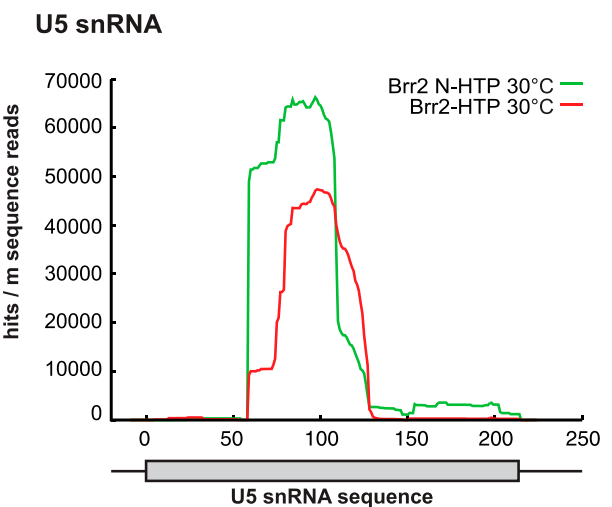

G

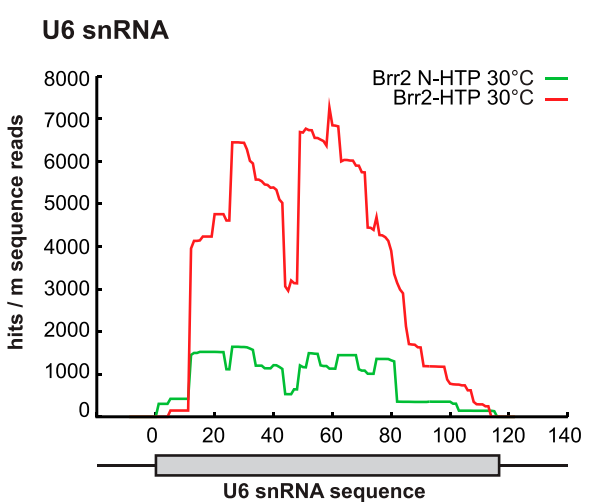

I

U2 snRNA

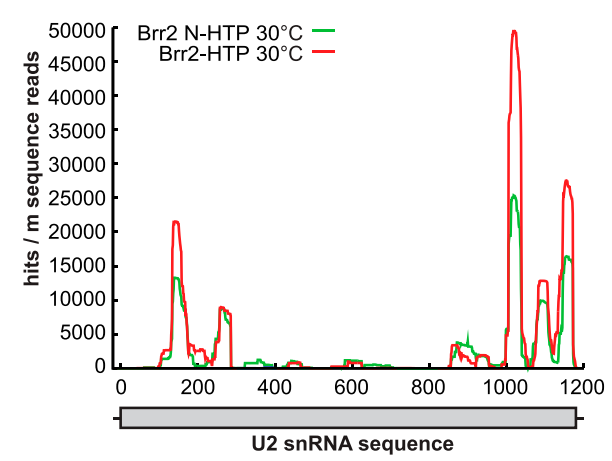

Figure 1. Identification of Brr2p-RNA interaction sites by in vivo cross-linking and sequencing. (A) Schematic of HTP-tagged Brr2p and Brr2p fragments used in cross-linking experiments. $(B-E)$ Summary of sequencing data for cDNA libraries generated from RNAs cross-linked to Brr2-HTP $30^{\circ} \mathrm{C}$, Brr2 N-HTP $30^{\circ} \mathrm{C}$, Brr2 C-HTP $30^{\circ} \mathrm{C}$, or the untagged $30^{\circ} \mathrm{C}$ control (cultures grown at $30^{\circ} \mathrm{C}$ ). Pie charts indicate proportions of sequences corresponding to functional RNA classes. $(B, C)$ Values are based on high-throughput sequencing. $(D, E) \operatorname{Brr} 2 \mathrm{C}-\mathrm{HTP} 30^{\circ} \mathrm{C}$ and the control sample did not produce usable data sets by high-throughput sequencing. Thus, cDNAs were TAcloned and analyzed by Sanger sequencing. $(F-I)$ Distribution of sequencing reads in snRNAs identified in Brr2-HTP $30^{\circ} \mathrm{C}$ and Brr2 N-HTP $30^{\circ} \mathrm{C}$ CRAC experiments. The number of hits per million sequence reads is plotted against the nucleotide sequence of indicated snRNAs. 
Although, the two cassettes are predicted to adopt a similar overall organization (Pena et al. 2009), they differ in some important features. In $\mathrm{H} 2$, the conserved motifs characteristic of DExH-box helicase domains deviate from the consensus, and mutations that would be expected to impair helicase activity do not affect Brr2p function or cell viability (Kim and Rossi 1999). This suggested that, in contrast to $\mathrm{H} 1, \mathrm{H} 2$ lacks functional helicase activity. Whether $\mathrm{H} 2$ engages in direct RNA interactions was unknown until now, but it does form important protein interactions (van Nues and Beggs 2001; Liu et al. 2006), suggesting that this may be its major function (Pena et al. 2009).

Here we identify direct Brr2p-RNA interactions in Saccharomyces cerevisiae by in vivo UV cross-linking and sequencing (CRAC) (Granneman et al. 2009). Our findings indicate that only the $\mathrm{N}$-terminal helicase cassette of Brr2p interacts with RNA, and we present evidence that Brr2p initiates $\mathrm{U} 4 / \mathrm{U} 6$ disruption by translocating on U4 and unwinding U4/U6 stem I. Moreover, our data suggest a novel function for Brr2p in promoting conformational rearrangements in the spliceosome during the first-to-second-step transition, which aid 3' splice site ( $3^{\prime}$ SS) positioning and formation of the second-step catalytic center.

\section{Results}

Full-length Brr2p and the N-terminal helicase cassette show similar RNA interaction patterns

In order to identify RNA interactions established by the $\mathrm{N}$-terminal and C-terminal helicase cassettes of Brr2p, we generated yeast strains in which the two halves of Brr2p are expressed independently. Fusing either the $\mathrm{N}$-terminal or C-terminal part of Brr2p to the HTP tag allowed purification of only the tagged region and identification of interacting RNAs (Fig. 1A). Coexpression of the two halves fully complemented a BRR2 deletion and supported growth rates comparable with the wild type (Supplemental Fig. S1A). Pull-down experiments showed that the two halves efficiently heterodimerize (Supplemental Fig. S1B). Primer extension analysis detected wild-type levels of mRNA without detectable pre-mRNA accumulation, indicating that splicing activity was unaffected (Supplemental Fig. S1C). The physically separated helicase cassettes therefore reconstituted functional Brr2p in vivo.

We performed CRAC experiments with full-length Brr2-HTPp, with the tagged halves of Brr2p, and with a nontagged negative control using cultures grown and crosslinked at $30^{\circ} \mathrm{C}$. Cross-linked protein-RNA complexes were recovered by two-step purification, RNAs were reversetranscribed, and cDNA libraries were generated (Supplemental Fig. S1D,E). Libraries generated with the Brr2-HTP $30^{\circ} \mathrm{C}$ and Brr2 N-HTP $30^{\circ} \mathrm{C}$ samples were Solexa-sequenced. However, the nontagged control and Brr2 C-HTP $30^{\circ} \mathrm{C}$ samples did not produce usable Solexa sequence data sets, likely due to insufficient cDNA concentrations, and were therefore TA-cloned and Sanger-sequenced.

Recovered sequences were aligned to the genome and assigned to different categories based on RNA function
(Fig. 1B-E). cDNAs recovered with the nontagged strain (159 clones) and Brr2 C-HTP $30^{\circ} \mathrm{C}$ (193 clones) mainly consisted of rRNA and tRNA sequences (Fig. 1D,E), which are common contaminants in CRAC analyses (Granneman et al. 2009). In contrast, in the Brr2-HTP $30^{\circ} \mathrm{C}$ and Brr2 $\mathrm{N}$-HTP $30^{\circ} \mathrm{C}$ data sets, the majority of sequences represented snRNAs $(80 \%$ and $67 \%$, respectively) (Fig. 1B,C). Comparison of the hit densities for the Brr2-HTP and Brr2 N-HTP proteins over the U4, U6, U5, and U2 snRNAs shows closely related distributions (Fig. 1F-I). We conclude that only the N-terminal helicase cassette of Brr2p establishes direct RNA interactions, and these are the same as full-length Brr2p. The lack of RNA interactions with the C-terminal cassette is consistent with it functioning solely as a protein interaction domain.

\section{Interaction sites in U4 indicate U4/U6 stem I as a Brr2p substrate}

Brr2p interaction sites on U4 and U6 are indicated in the U4/U6 structure (Fig. 2A-C). Sequence reads representing U4 snRNA were highly abundant and clustered in two regions. One of these (nucleotides 30-75) encompasses the $3^{\prime}$ side of the $5^{\prime}$ stem-loop (5' SL), the U4 side of U4/ U6 stem I, and part of the central domain. The other (nucleotides 128-158) includes part of the 3' side of the 3' SL. Deletions and substitutions are frequently recovered at the precise location of cross-linking, with deletions being most informative, and their mapping suggests nucleotide U138 as a direct Brr2p-U4 contact site (Fig. 2A,C). Sequences representing U6 snRNA were recovered at substantially lower frequency than U4. Hits covered nucleotides 13-80, including the U6 side of U4/U6 stems I and II, but showed two distinct peaks separated by a reduced signal over nucleotides 44-48 (Fig. 2B).

The identification of Brr2p interactions in U4 and U6 is consistent with the suggestion that Brr2p is involved in unwinding the U4/U6 duplex during spliceosome activation. Based on comparative analyses of Ski2-like helicases, Brr2p is expected to possess $3^{\prime}$-to-5' directionality (Pena et al. 2009). In principle, Brr2p could translocate on either U6 or U4. Translocation on U6 would imply successive unwinding of U4/U6 stem II before stem I. Translocation on U4 would imply that Brr2p disrupts stem I before reaching the $5^{\prime}$ SL. In this case, unwinding of stem II would demand prior disruption of the U4 5' SL. Brr2p interaction sites were identified in the central domain, stem I, and 5' SL areas of U4 but not on the U4 side of stem II (Fig. 2C), making it implausible that stem II is a substrate of Brr2p. This in turn suggests that Brr2p may unwind only stem I.

Structural analyses of the $S$. cerevisiae U4/U6:U5 trisnRNP suggested that U4/U6 stem II coaxially stacks on the U4 5' SL, forming a separate domain from stem I (Lescoute and Westhof 2006; Häcker et al. 2008). Therefore, to investigate the importance of the U4 3' SL for Brr2p interaction with the U4/U6 duplex, we performed electrophoretic gel mobility shift assay (EMSA) experiments using Brr2 protein purified from yeast (Supplemental Fig. S2) with in vitro transcribed RNAs. Brr2p did not detect- 
A

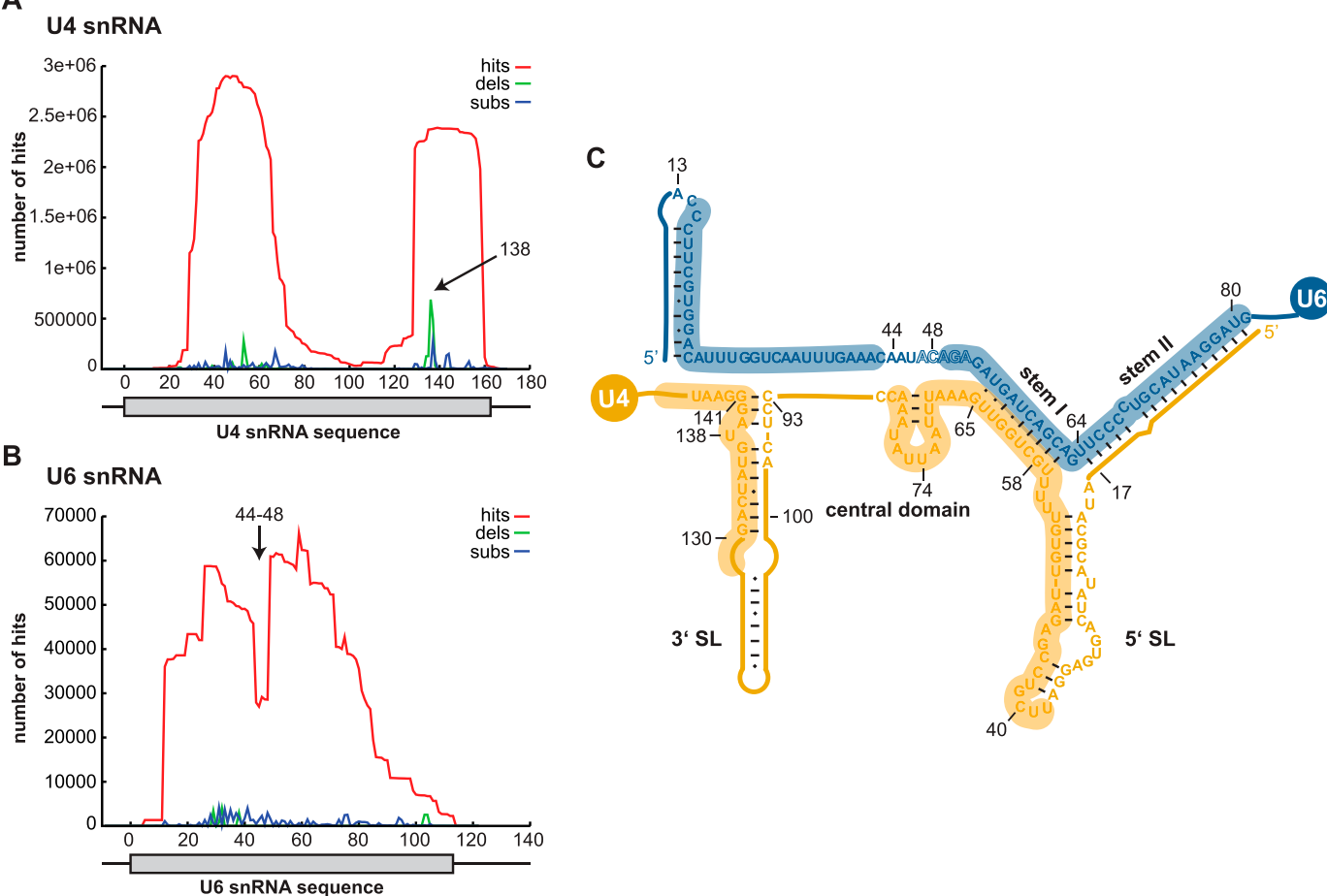

D

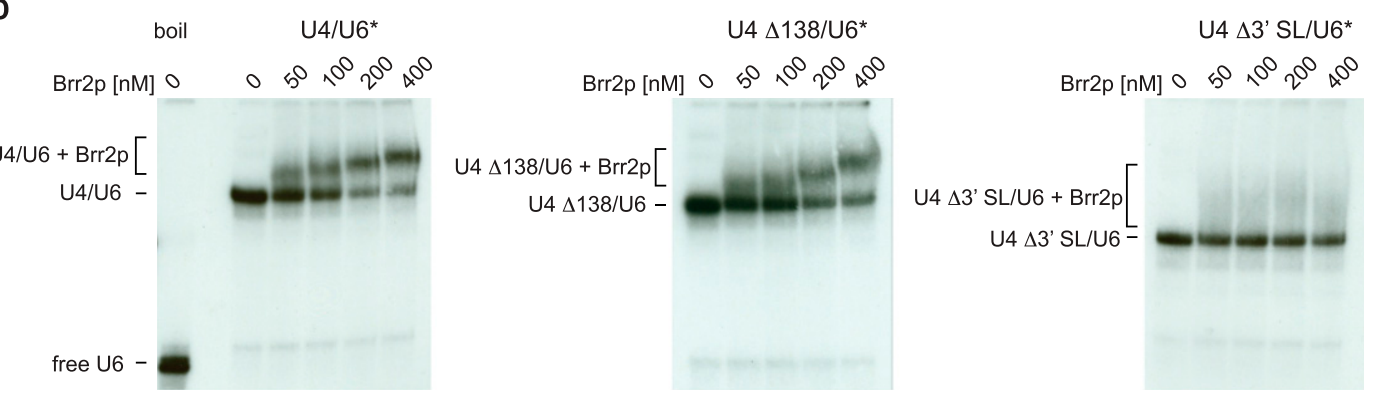

Figure 2. Brr2p cross-links in U4 and U6 snRNAs overlap in U4/U6 stem I. Distribution of sequencing reads in U4 (A) and U6 (B) snRNAs in Brr2-HTP $30^{\circ} \mathrm{C}$ CRAC experiment. Red graphs represent the number of hits per nucleotide of the indicated snRNA. Green and blue graphs indicate deletions and substitutions, respectively. $(C)$ Secondary structure of $S$. cerevisiae U4/U6 snRNA duplex. Yellow and blue shading indicates putative Brr2p interactions. $(D)$ EMSA tests the association of purified yeast Brr2p with wild type (WT) or the mutant U4/U6 duplex. Increasing amounts of Brr2p were combined with the indicated RNA duplex (asterisk marks ${ }^{32}$ P-labeled RNA). Protein-RNA complexes were resolved by native PAGE.

ably bind to either U4 or U6 snRNA individually (data not shown). However, Brr2p associated well with duplexed U4/U6 and with a U6/U4 $\Delta$ U138 mutant duplex, which lacks a bulged nucleotide in the U4 3' SL within the region cross-linked by Brr2p (Supplemental Fig. S2). We conclude that the bulged nucleotide U138 at the top of the stem, although directly contacted by Brr2p, is not itself a prerequisite for Brr2p binding to U4/U6. In contrast, deletion of the entire U4 3' SL (nucleotides 93-141) strongly reduced Brr2p association with the U4/U6 duplex (Fig. 2D). As Brr2p did not associate with U4 3' SL by itself in EMSA (data not shown), this part of U4 is not by itself sufficient to mediate binding in vitro, suggesting that another part (or parts) of the U4/U6 heteroduplex is also required.

U4 mutations that impair spliceosome activation are synthetic-lethal (sl) with mutations that compromise Brr2p function (Kuhn et al. 1999). We therefore assessed the viability of various combinations of brr2 and U4 mutants (Supplemental Table S1; Supplemental Fig. S2E-K). Point mutations and local deletions within the U4 3' SL were not synergistically lethal with brr2 alleles, suggesting that minor changes in the stem do not adversely affect Brr2p function. In contrast, deletion of the entire U4 3' SL was lethal, even in the presence of wild-type $B R R 2$ (Supplemental Table S1), supporting the biochemical evidence that the absence of the U4 3' SL structure affects Brr2p-U4/U6 interactions.

Brr2p interacts physically, genetically, and functionally with loop 1 of U5 SnRNA

Brr2p hits in U5 snRNA showed numerous deletions at U96 in the highly conserved and functionally important 
Hahn et al.

loop 1 region (Fig. 3A,B), identifying this as a major contact site. U5 loop 1 is dispensable for the first step of splicing but is required for the second step, where it facilitates exon positioning (O'Keefe et al. 1996; Newman 1997). To query whether Brr2p participates in this function, we tested genetic interactions between U5 loop 1 mutants and conditional brr2 alleles. Among the five alleles tested, brr2-G858R was sl with several U5 loop 1 mutations (Fig. 3C; Supplemental Table S2).

Multiple brr2 mutants were previously shown to have a block prior to the first step of splicing due to inefficient U4/U6 unwinding (Raghunathan and Guthrie 1998; Pena
A

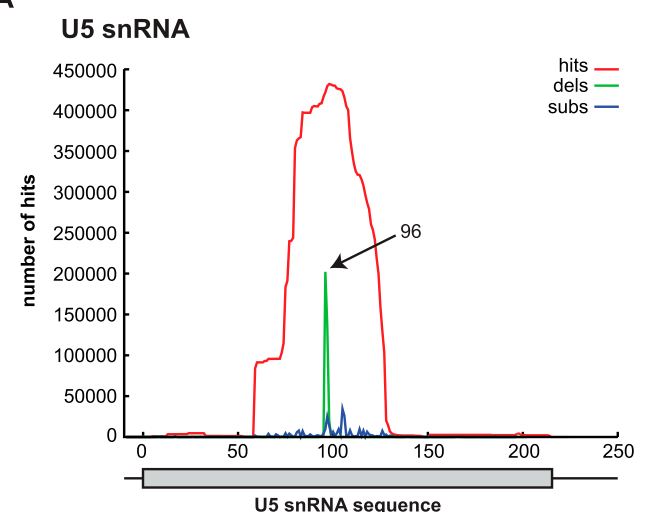

D

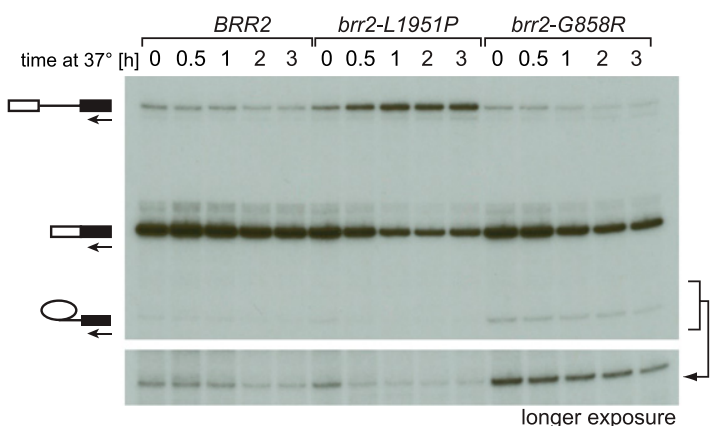

E

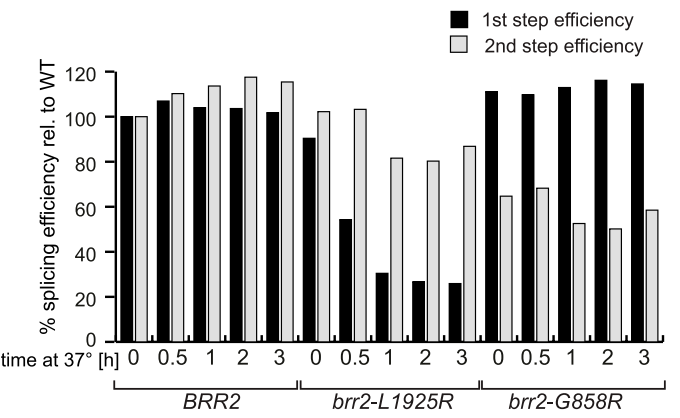

B

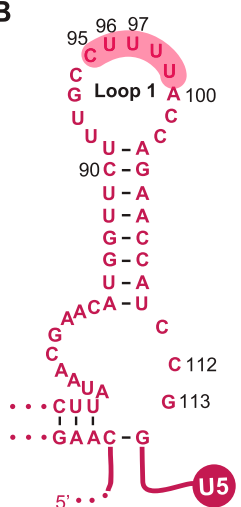

C

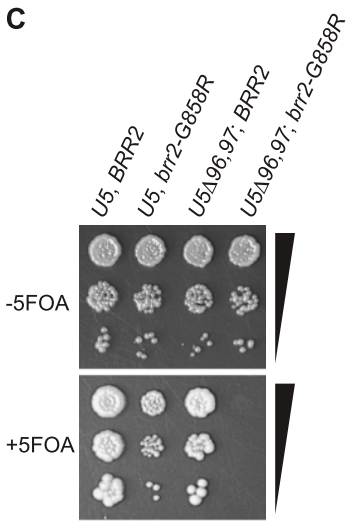

$\mathbf{F}$

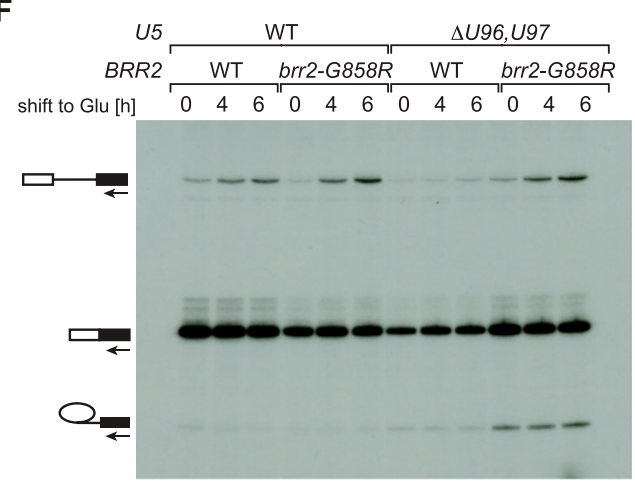

G

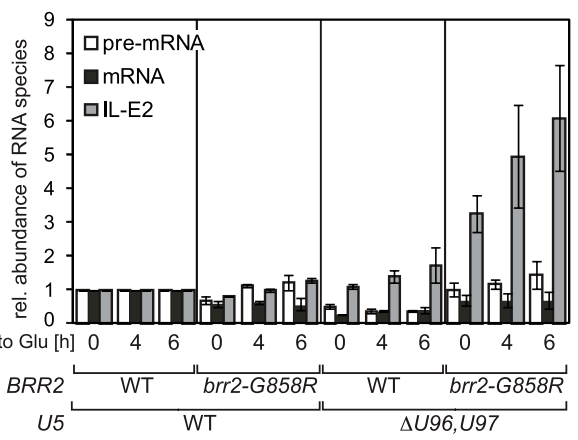

Figure 3. Brr2p interacts physically and functionally with U5 loop 1. (A) Distribution of sequencing reads in U5 snRNA in Brr2-HTP $30^{\circ} \mathrm{C}$ CRAC experiment. The red graph indicates the number of hits per nucleotide of U5 snRNA. Green and blue graphs indicate deletions and substitutions, respectively. (B) Structure of $S$. cerevisiae U5 snRNA stem-loop 1 and the putative Brr2p interaction site (red shading). (C) Serial dilutions of the indicated strains were spotted to agar lacking or containing 5-fluoorotic acid (5FOA) for plasmid shuffle. Plates were incubated for $2 \mathrm{~d}$ at $30^{\circ} \mathrm{C}$. (D) Primer extension of ACT1-CUP1 reporter (Lesser and Guthrie 1993) reveals reduced second-step splicing efficiency of brr2-G858R. The indicated strains were grown at $25^{\circ} \mathrm{C}$ and shifted to $37^{\circ} \mathrm{C}$ for the indicated duration. Symbols on the left indicate migration of RNA species. $(E)$ Quantification of results shown in $D$. First-step efficiency was calculated as $(\mathrm{M}+\mathrm{IL}-\mathrm{E} 2) /(\mathrm{P}+\mathrm{M}+\mathrm{IL}-\mathrm{E} 2)$, where $\mathrm{P}$ is pre-mRNA, $\mathrm{M}$ is $\mathrm{mRNA}$, and IL-E2 is intron-lariat exon 2. Second-step efficiency was calculated as $M /(M+I L-E 2)$. Values were normalized to the respective efficiencies of the wild type (WT) at t0, set as 100. (F) Primer extension of ACT1-CUP1 reporter shows the accumulation of IL-E2 when the combination of U5 $\Delta 96,97$ and brr2-G858R becomes limiting for growth (see also Supplemental Fig. S3C). (G) Quantification of results shown in F. Values are normalized to wild-type BRR2 and wildtype U5 at t0. Diagram shows averages of three independent experiments; error bars indicate standard deviation. 
et al. 2009). However, the extensive genetic interactions between brr2-G858R and U5 loop 1 alleles suggested that it might affect splicing after the first step. Primer extension assays revealed that brr2-G858R caused moderate accumulation of the lariat intron-exon 2 (IL-E2) first-step product (Fig. 3D,E; Supplemental Fig. S3A,B), confirming that brr2-G858R provokes a second-step splicing defect. We reasoned that IL-E2 might be susceptible to rapid turnover and therefore tested whether removal of the debranching enzyme Dbrlp might increase its accumulation. However, brr2-G858R was lethal in a $d b r 1 \Delta$ background (Supplemental Fig. S3D). Conceivably, high accumulation of step 1 splicing products in the brr2G858R, dbr1s strain may give rise to the sl phenotype.

Metabolic depletion of Brr2p combined with plasmid shuffle (see the Supplemental Material) was used to assess the effect of combining brr2-G858R with U5 $\Delta 96,97$. A higher accumulation of IL-E2 was seen in the double mutant than for either single mutation, indicating an enhanced second-step splicing defect (Fig. 3F,G).

\section{brr2-G858R interacts genetically with second-step factors}

Extending the genetic analysis to other second-step factors, we found sl interactions between brr2-G858R and mutant alleles of SLU7, PRP18, and PRP16 (Fig. 4). Slu $7 \mathrm{p}$ and Prp18p are proposed to aid alignment of the exons relative to U5 loop 1 , thereby stabilizing the second-step conformation (Bacikova and Horovitz 2005; Crotti et al. 2007). Prp16p activity promotes the first-tosecond-step transition by eliciting conformational rearrangements that lead to protection of the $3^{\prime}$ SS from oligonucleotide-directed RNase $\mathrm{H}$ cleavage (Schwer and Guthrie 1992). These genetic interactions are therefore consistent with a defect prior to or at step 2 in brr2G858R cells.

\section{Brr2p cross-links near SSs}

To investigate whether brr2-G858R affects Brr2p-RNA interactions at the catalytic center, we performed CRAC on the HTP-tagged Brr2-G858R mutant protein. As brr2G858R cells accumulate IL-E2 even at the permissive temperature (Fig. 3D), in vivo cross-linking was performed on cultures grown at $25^{\circ} \mathrm{C}$ or shifted for $1 \mathrm{~h}$ to $37^{\circ} \mathrm{C}$. Sequencing libraries were generated using barcoded $5^{\prime}$ adapters and were sequenced together to permit a direct comparison (Fig. 5A-C; Supplemental Fig. S4A,B). Unfortunately, data sets obtained with the barcodes of the nontagged control and Brr2-HTP $37^{\circ} \mathrm{C}$ could not be separated unambiguously and were omitted from further analysis.

In the Brr2-G858R-HTP data sets, a higher proportion of sequences represented mRNAs relative to wild-type Brr2-HTP (Fig. 5A-C), with intron-containing transcripts being highly enriched compared with intron-less transcripts (Supplemental Fig. S4C-H). Exon-exon sequence reads that spanned splice junctions were highly underrepresented compared with exon-intron and intron-exon junctions (data not shown), showing that Brr2p interacts with unspliced and partially spliced but not spliced messages. We conclude that these Brr2-G858Rp cross-links occur within spliceosomes.

For many transcripts, cross-links were preferentially localized near SSs and in the region between the branch point (BP) and 3' SS (Fig. 5D,E). The enrichment in hit density near SSs was much more pronounced for Brr2G858Rp than for wild-type Brr2p. Furthermore, at the 3' ends of introns, the cross-linked region extended from the $\mathrm{BP}$ to the vicinity of the 3' SS (Fig. 5D-F). Cross-links at the $5^{\prime}$ ends of introns were also more abundant for Brr2G858Rp. In branched IL-E2 species, the 5' end of the intron is covalently attached to the BP and hence is very close in space. Thus, a single molecule of Brr2-G858Rp might cross-link to the $5^{\prime} \mathrm{SS}$, the $\mathrm{BP}$, the $3^{\prime} \mathrm{SS}$, or the intervening region in IL-E2. These observations suggested a potential function for Brr2p in repositioning these elements of the IL-E2 and/or remodeling their secondary structure during the first-to-second-step transition. This model is entirely compatible with the genetic data for brr2-G858R and the observed second-step splicing defect (Fig. 3D,E; Supplemental Fig. S3A,B).

\section{BP-3' SS distance and structure determine Brr2p dependence}

On completion of the first step of splicing, the BP structure is located in the active site of the spliceosome. To allow the second step, this must be removed and replaced by the 3' SS (Smith et al. 2008). These repositioning events are potentially more difficult for transcripts with long BP-to-3' SS distances and were shown to depend on secondary structure formation between the BP and 3' SS
A

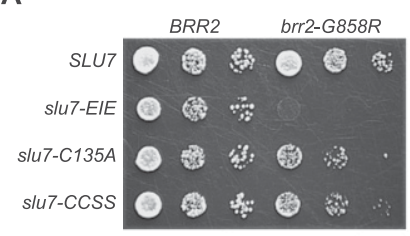

B

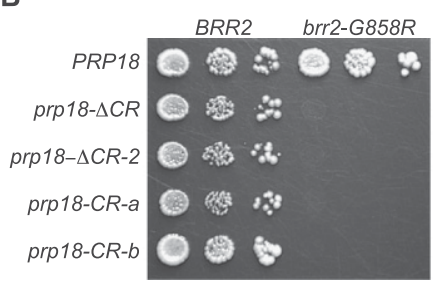

C

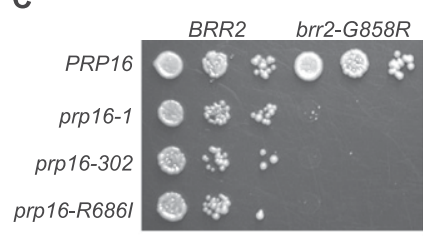

Figure 4. Genetic interactions between brr2-G858R and second-step factors. Plasmid shuffle assays identify sl interactions between pairs of BRR2, PRP16 $(A) ; B B R 2, S L U 7(B)$; and BRR2, PRP18 $(C)$ alleles. The indicated alleles were introduced into the respective double-deletion strains containing wild-type $(\mathrm{WT})$ alleles on URA3 plasmids. Serial dilutions of the indicated strains were spotted to agar containing $5 \mathrm{FOA}$ and grown for $2-3 \mathrm{~d}$ at $30^{\circ} \mathrm{C}$. 
Hahn et al.

A

\section{Brr2-HTP $25^{\circ} \mathrm{C}$}

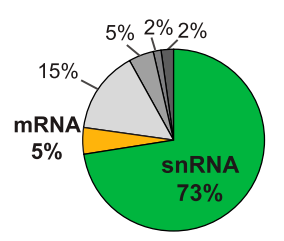

[1.8 million]
B

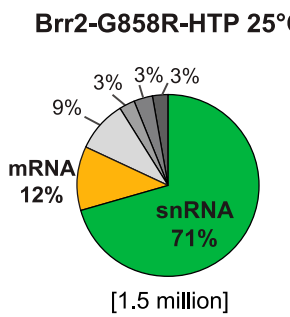

D

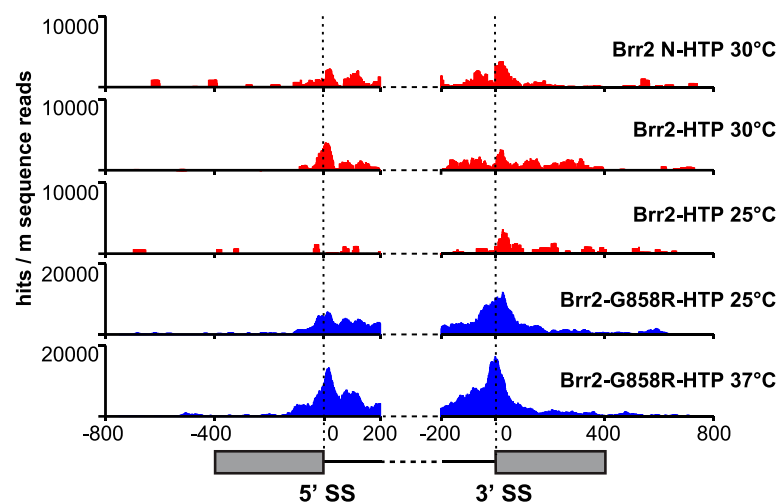

$C_{\text {Brr2-G858R-HTP } 37^{\circ} \mathrm{C}}$

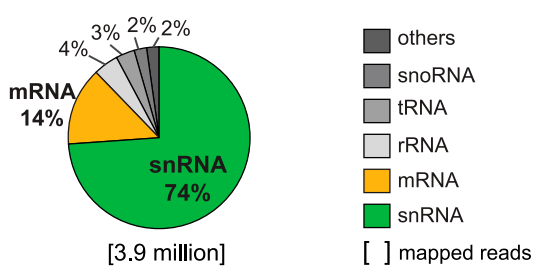

E

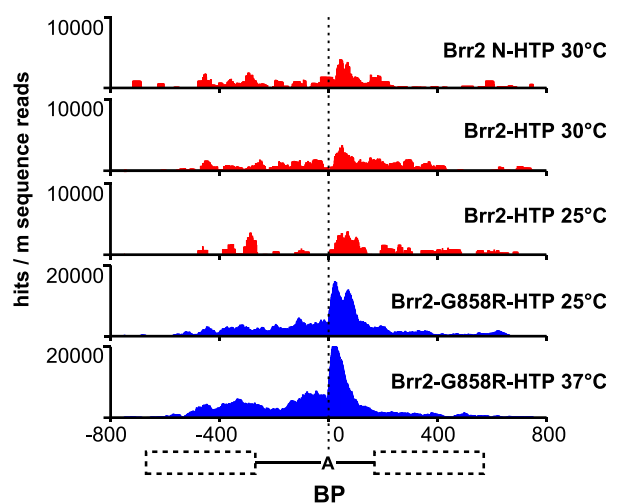

F

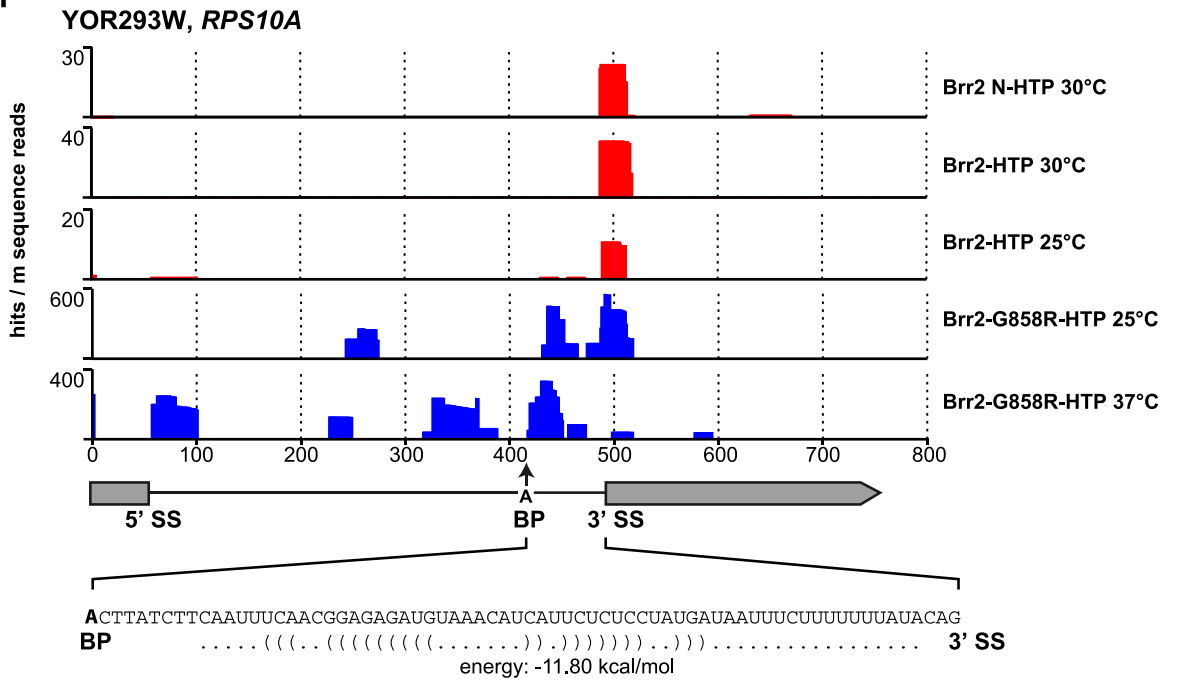

Figure 5. Brr2-G858Rp elevates cross-linking near SSs. High-throughput sequence analysis of cDNA libraries generated from RNAs cross-linked to Brr2-HTP $25^{\circ} \mathrm{C}(\mathrm{A})$, Brr2-G858R-HTP $25^{\circ} \mathrm{C}(\mathrm{B})$, and Brr2-G858R-HTP $37^{\circ} \mathrm{C}(\mathrm{C})$. Pie charts show the proportions of sequences mapped to different functional RNA classes. $(D, E)$ Hit densities near SSs. The number of hits per million sequence reads (indicated data sets) was plotted against the genomic sequences surrounding SSs ( $\pm 800 \mathrm{nt}$ ) cumulated for all introns annotated in the $S$. cerevisiae genome. Genomic loci were aligned relative to the $5^{\prime} \mathrm{SS}(D$, left $)$, the $3^{\prime} \mathrm{SS}(D$, right $)$, and the BP $(E)$. Note the twofold change in scale for Brr2-G858R-HTP data sets. $(F)$ Hit distribution in a representative transcript. The number of hits per million sequence reads (indicated data sets) per nucleoted of the YOR293w ORF. The predicted secondary structure between the BP and 3' SS according to Meyer et al. (2011) is indicated below the graph.

for a subset of transcripts in yeast (Meyer et al. 2011). If Brr2-G858Rp impairs lariat repositioning, splicing of this class of transcript should be preferentially inhibited, resulting in reduced mRNA synthesis.

We performed RNA sequencing (RNA-seq) analyses on poly $(\mathrm{A})^{+}$-selected RNA from brr2-G858R and wild-type $B R R 2$ strains grown at the permissive temperature. Sequence coverage over protein-coding transcripts was com- pared between mutant and wild-type $B R R 2$. Intron-less transcripts were unaffected in brr2-G858R cells, whereas intron-containing transcripts were significantly depleted $\left(P<2.2 \times 10^{-16}\right.$, Wilcoxon test) (Fig. 6A), in keeping with a splicing-dependent effect. However, not all intron-containing transcripts were affected equally. Intron-containing transcripts that are predicted to be structured between the BP and 3' SS (according to Meyer et al. 2011; Yeast 
A

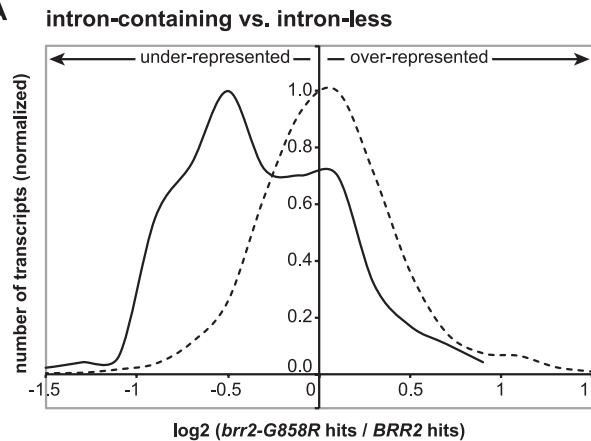

B

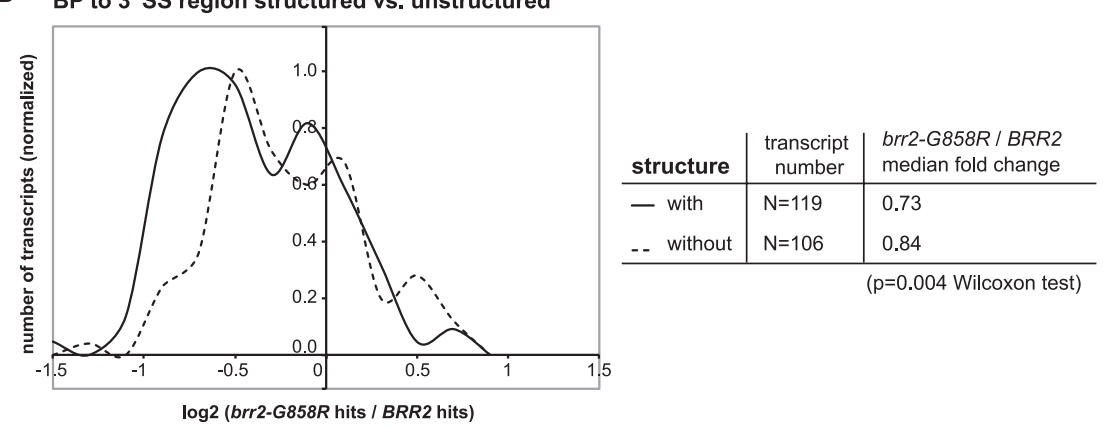

Figure 6. Intron-containing transcripts that require structure formation between the $\mathrm{BP}$ and $3^{\prime}$ SS are depleted in the presence of Brr2-G858Rp. Poly $(A)^{+}$-selected RNA from strains harboring brr2-G858R or wild-type (WT) BRR2 was analyzed by RNA-seq. Graphs show the distribution of the $\log 2$ fold change of transcript abundance in brr2G858R versus BRR2 strains. Numbers of transcripts are normalized, with the maximum value set as 1 . Transcripts are grouped into categories to compare intron-containing and intron-less transcripts $(A)$; introncontaining transcripts with or without the requirement for structure formation between the BP and 3' SS (B), based on Meyer et al. (2011); and intron-containing transcripts with short ( $\leq 34-n t)$ or long (>34-nt) BP-to-3' SS distances $(C)$. The $\log 2$ values of all intron-containing transcripts are listed in Supplemental Table S3.
C BP to 3' SS distance long vs. short

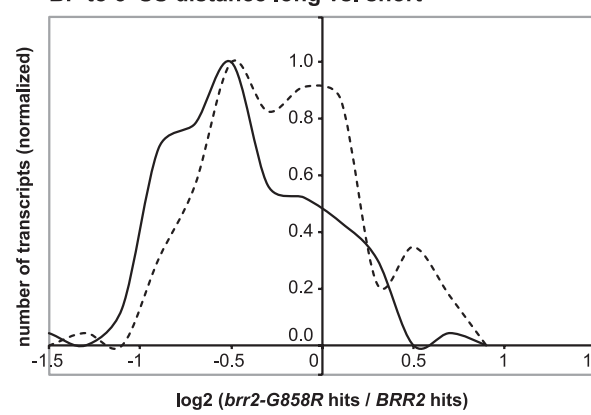

\begin{tabular}{l|l|l} 
BP to 3' SS & $\begin{array}{c}\text { transcript } \\
\text { number }\end{array}$ & $\begin{array}{l}\text { brr2-G858R / BRR2 } \\
\text { median fold change }\end{array}$ \\
\hline$->34 \mathrm{nt}$ & $\mathrm{N}=104$ & 0.72 \\
$--<=34 \mathrm{nt}$ & $\mathrm{N}=121$ & 0.86 \\
\hline \multicolumn{3}{|c}{$(\mathrm{p}=0.0002$ Wilcoxon test $)$}
\end{tabular}

Intron Structures Database, http://regulatorygenomics.upf. edu/yeast_introns) were reduced to a larger extent than nonstructured species $(P=0.004$, Wilcoxon test $)$ (Fig. 6B). Consistent with this, transcripts with long BP-to-3' SS distances (>34 nucleotides [nt]) were reduced to a larger extent than those with short BP-to-3' SS distances ( $\leq 34 \mathrm{nt}$; $P=0.0002$, Wilcoxon test) (Fig. 6C). The negative correlation between the BP-to-3' SS distance and mRNA fold change in brr2-G858R relative to BRR2 was highly significant $\left(\right.$ Spearman, $\rho=-0.32, P$-value $\left.=9.632 \times 10^{-7}\right)$. A summary of all intron-containing transcripts and the effect of brr2-G858R on expression levels is given in Supplemental Table S3.

Brr2-G858Rp alters the cross-linking pattern with U6 snRNA

Different nucleotide substitutions at position U57 of U6 snRNA have distinctly different splicing phenotypes.
U6-U57C improves the first step and inhibits the second step, whereas U6-U57A improves the second step and inhibits the first (McPheeters 1996; Query and Konarska 2004; Liu et al. 2007). We observed sl interactions of brr2G858R in combination with U6-U57C but no adverse effect in combination with U6-U57A (Fig. 7A), suggesting that brr2-G858R specifically inhibits progression to the second step.

Substrate repositioning for the second step of splicing was proposed to require transient disruption of basepairing interactions between the 5' SS and U6 (Konarska et al. 2006) and concomitant disruption of U2/U6 helix I (Mefford and Staley 2009). The cross-linking patterns of wild-type Brr2p and Brr2-G858Rp over U6 snRNA were compared for effects on the proposed transitional state. Brr2p predominantly interacted with nucleotides 15-43 and nucleotides 49-70, whereas the proportion of total hits over U6 was increased for Brr2-G858Rp, and the pattern was displaced. While the proportion of U6 hits 
Hahn et al.

A
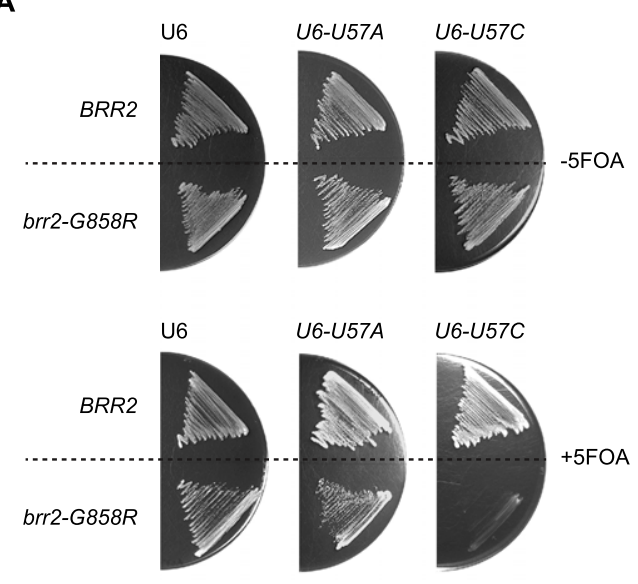

B

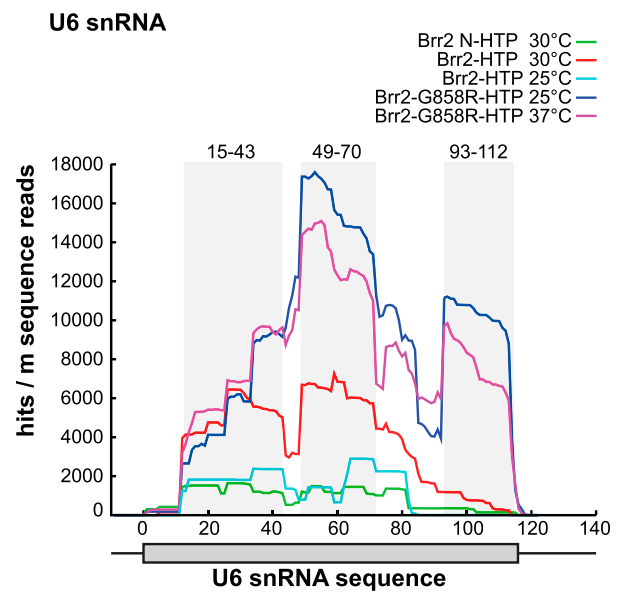

C
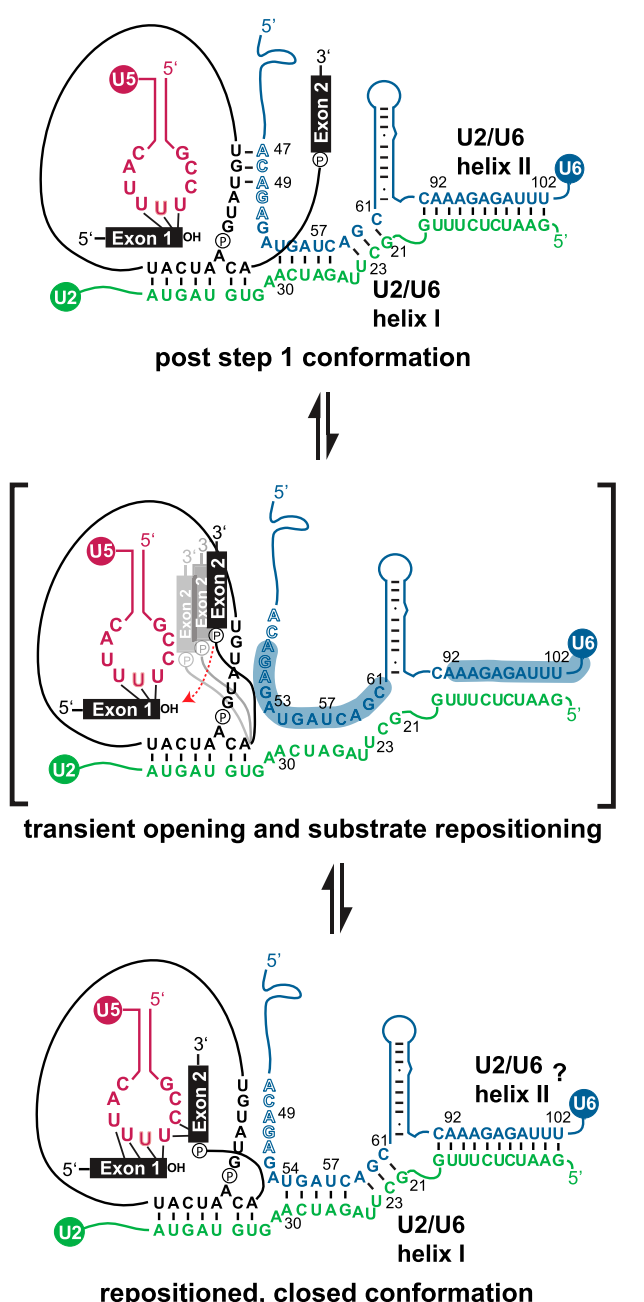

Figure 7. Brr2-G858Rp has an altered interaction profile on U6, suggesting that spliceosomes adopt a transient open conformation. (A) Genetic interactions between brr2 and U6 snRNA alleles. Strains carrying the indicated alleles plus wild-type (WT) alleles on URA3 plasmids were grown on plates lacking or containing 5FOA and incubated for $2 \mathrm{~d}$ at $30^{\circ} \mathrm{C}$. $(B)$ CRAC hit densities in U6 snRNA for Brr2 N-HTP $30^{\circ} \mathrm{C}$, Brr2-HTP $30^{\circ} \mathrm{C}$, Brr2-HTP $25^{\circ} \mathrm{C}$, Brr2-G858R-HTP $25^{\circ} \mathrm{C}$, and Brr2-G858R-HTP $37^{\circ} \mathrm{C}$. Plot shows the number of hits per million sequence reads along the U6 snRNA. (C, top to bottom) Model of conformational rearrangements during the first-to-secondstep transition. Formation of the second-step catalytic center requires transient opening of U6/5' SS and U2/U6 helix I interactions (Konarska et al. 2006; Mefford and Staley 2009). This allows repositioning of the branch structure and placing the 3' SS at the active site (dotted red arrow). Subsequently, U2/U6 helix I is re-established; it is not clear whether U2/U6 helix II and U6/5' SS interactions are reformed (Konarska et al. 2006; Mefford and Staley 2009). The cross-linking pattern and phenotype of brr2-G858R suggest an impairment in this transition, reducing second-step efficiency and prolonging the open state in which the BP-to-3' SS region is remodeled such that U6 regions that form U2/U6 helix I and II are accessible for cross-linking (blue shading).

over nucleotides 15-43 was reduced, Brr2-G858Rp showed a strongly elevated signal over nucleotides 49-61, and a second peak appeared over nucleotides 93-112 (Fig. 7B). Much less marked differences were observed between mutant and wild-type Brr2p cross-links with the other spliceosomal snRNAs, with changes being seen in overall number of hits rather than in hit distribution (Supplemental Fig. S5). Therefore, Brr2-G858Rp and wild-type Brr2p make substantially different contacts specifically with U6, consistent with increased accessibility of U6 for cross-linking in mutant cells. Notably, regions of enhanced cross-linking correspond to parts of U6 that form U2/U6 helices in active spliceosomes.
The specific genetic interactions of brr2-G858R in combination with enhanced contact of Brr2-G858Rp with U6 elements that form U2/U6 interactions would be consistent with the model that Brr2-G858Rp stabilizes the transient open state of the spliceosome that is proposed to exist during the first-to-second-step transition (Fig. 7C; Konarska et al. 2006).

\section{Discussion}

The in vivo cross-linking approach used here produced an inventory of the RNA interactions established by Brr2p transcriptome-wide, potentially identifying all 
Brr2p substrates. Cross-links to U4, U5, or U6 snRNAs could, in principle, occur within tri-snRNPs, spliceosomes, or post-splicing complexes. However, cross-links to intron sequences can be assumed to occur within spliceosomes, and cross-links to IL-E2 intermediates indicate contacts occurring prior to second-step catalysis in spliceosomes. Analysis of a mutant brr2 strain with a second-step splicing defect suggests that Brr2p contributes to remodeling the catalytic center, offering insights into the transition state between the two splicing reactions.

\section{Only the N-terminal helicase cassette of Brr2p interacts with RNA}

In the cross-linking analyses with the separated helicase cassettes of Brr2, only the N-terminal helicase cassette interacted with RNA and almost entirely reproduced the interactions seen with the full-length protein (Fig. 1B-I). In contrast, the isolated C-terminal cassette showed no interactions with RNA but was required for viability (Supplemental Fig. S1A; Zhang et al. 2009). Consistent with this, the $\mathrm{N}$-terminal helicase cassette has predicted surface charges that support nucleic acid interactions, whereas the surface of the C-terminal helicase cassette is unfavorable for nucleic acid interactions (Pena et al. 2009). Thus, following a duplication event, the C-terminal half of Brr2p may have lost its helicase activity and evolved as a protein interaction domain.

\section{Brr2p-mediated U4/U6 dissociation mechanism}

Disruption of the U4/U6 duplex, a critical step in spliceosome activation, is thought to be catalyzed by Brr2p. In principle, Brr2p could initiate dissociation by unwinding U4/U6 stem II while translocating on U6 or by unwinding stem I while translocating on $\mathrm{U} 4$. Our in vivo Brr2p-U4 cross-linking interactions (Fig. 2A) support translocation on $\mathrm{U} 4$ and unwinding of stem I. Consistent with this, a functional link between U4/U6 stem I stability and Brr2p activity was indicated previously by the sl interaction of the ATPase-defective brr2-1 allele with a mutation in U4 (cs-1) that hyperstabilizes stem I (Kuhn et al. 1999). Significantly, in U12 spliceosomes, disruption of the structurally analogous U4atac/U6atac stem Ia was shown to occur prior to opening of stem II (Frilander and Steitz 2001). This order of events allows the establishment of U6/U2 interactions and U6/5' SS interactions (which are mutually exclusive with U4/U6 stem I) prior to disruption of U4/U6 stem II. Indeed, previous studies of the yeast $\mathrm{U} 2$ spliceosome were interpreted as showing that establishment of U6/5' SS interactions is essential to complete U4/U6 unwinding (Kuhn et al. 1999; Staley and Guthrie 1999). However, attempts to demonstrate sequential unwinding of stems I and II in U2 spliceosomes have been unsuccessful, possibly due to differences in the U2/U6 interactions in the two types of spliceosomes (Frilander and Steitz 2001). If Brr2p unwinds only stem I, other factors likely provoke dissociation of stem II. For example, following disruption of stem I, displacement of proteins from the U4 5' SL could destabilize U4 5' SL and stem II (Nottrott et al. 2002).

Many Brr2p cross-links mapped to the U4 3' SL (Fig. 2A), which may function as a docking site for Brr2p. Although the isolated 3' SL was not sufficient for Brr2p binding, deletion of this structure strongly reduced the interaction of Brr2p with the U4/U6 duplex in vitro (Fig. 2D). Notably, the U4 3' SL is implicated in tri-snRNP formation and/or stability (Hayduk et al. 2012). We speculate that Brr2p binding to the U4 3' SL may link U4/U6 to the U5 snRNP and position Brr2p relative to U4/U6 stem I. Brr2p could then readily "load" onto the central domain of U4 and unwind U4/U6 stem I by translocating in a $3^{\prime}$-to-5' direction. In a parallel study, Mozaffari-Jovin et al. (2012) reached the same conclusion about the mechanism for U4/U6 unwinding by Brr2p. In their EMSA, truncation of the $3^{\prime}$ end of $\mathrm{U} 4$, including deletion of the 3' SL, only slightly reduced Brr2p binding; however, as our RNA duplex substrates are different, they should not be directly compared. Conceivably, optimum unwinding by Brr2p may require both the U4 3' SL and the $5^{\prime}$ end of U6.

Apart from its function in U4/U6 unwinding during spliceosome activation, Brr2p was also suggested to promote spliceosome disassembly by destabilizing U2/U6 base-pairing (Small et al. 2006). However, no Brr2p interaction sites were detected in regions of $U 2$ that engage in base-pairing interactions with $\mathrm{U} 6$ or with the $\mathrm{BP}$ region (Fig. 1I; Supplemental Fig. S5C; Kudla et al. 2011). This suggests that the proposed role of Brr2p in post-catalytic $\mathrm{U} 2 / \mathrm{U} 6$ unwinding may be indirect.

\section{Spliceosomes 'caught' during the first-to-second-step transition}

During the transition between the first and second steps of splicing, the catalytic center must be remodeled, repositioning the products of the first trans-esterification reaction as substrates for the second reaction. The free $5^{\prime}$ exon apparently remains in the catalytic center, adjacent to U5 loop 1, whereas the IL-E2 must be moved to allow positioning of its 3' SS at the catalytic site for the second trans-esterification reaction. These remodeling events can be divided into distinct phases, including "opening" of the catalytic center followed by "substrate repositioning" (for review, see Smith et al. 2008). Elaborate genetic studies suggest that "opening" the catalytic center involves transient disruption of base-pairing interactions between U6 and the $5^{\prime}$ SS (Konarska et al. 2006) and of U2/U6 helix I (Fig. 7C; Mefford and Staley 2009). The ATPase Prp16p was proposed to catalyze disruption of U2/U6 helix I (Mefford and Staley 2009). Additional protein factors that stabilize RNA conformations in the catalytic center may also have to be displaced (Rasche et al. 2012). However, there are no published biochemical data to support the existence of the proposed open intermediate state.

The brr2-G858R allele is unusual in causing a secondstep defect (Fig. 3D,E; Lin and Rossi 1996), and sl interactions were found between brr2-G858R and prp16 as 
well as with other mutations affecting the second step (Figs. 4, 7A). Together, these results support the model that Brr2p is directly involved in remodeling the catalytic center prior to the second trans-esterification reaction. Brr2-G858Rp displayed an altered interaction profile with U6 snRNA compared with wild-type Brr2p, (Fig. 7B), with cross-linking primarily seen at nucleotides $49-61$ that base-pair with U2 in active spliceosomes (Fig. 7C). The increased interaction of Brr2-G858Rp at these sites could be explained if the brr2-G858R mutation prolongs a normally transient interaction with U6. The apparently increased accessibility of this region of U6 in the presence of Brr2-G858Rp is also consistent with the existence of an intermediate open conformation. In support of this, the cross-linking pattern of Brr2-G858Rp in intron-containing transcripts can be reconciled with cross-linking to IL-E2 intermediates (Fig. 5). We therefore propose that the splicing defect in brr2-G858R strains causes spliceosomes to stall in a normally transient open conformation.

The U6 region nucleotides $92-102$ base-pairs to the $5^{\prime}$ end of U2 to form U2/U6 helix II. A different brr2 allele, slt22-1, was sl with mutations that affect the stability of this helix, suggesting a role for Brr2p in proofreading U2/ U6 interactions (Xu and Friesen 2000). As Brr2-G858Rp cross-links were enriched over U6 nucleotides 93-112 but not at the $5^{\prime}$ end of U2, we speculate that U2/U6 helix II might not persist throughout the first-to-second-step transition.

\section{Brr2p preferentially affects step 2 splicing of introns} with structured $3^{\prime}$ ends

In yeast introns, the optimum BP-to-3' SS distance is 10$45 \mathrm{nt}$, but introns with longer BP-to-3' SS distances can achieve the optimum effective distance through secondary structure formation (Gahura et al. 2011; Meyer et al. 2011). RNA-seq analysis in strains carrying brr2-G858R revealed reduced levels of a subset of spliced mRNAs (Fig. 6), suggesting that these transcripts are inefficiently spliced and/or preferentially degraded. Notably, the affected transcripts were strongly enriched for introns with long and structured sequences between the BP and 3' SS (Fig. 6B,C; Supplemental Table S3). In addition, Brr2G858Rp cross-links that mapped downstream from BPs and around 3' SSs (Fig. 5D,E; Supplemental Fig. S4H-K) included sequences demonstrated or predicted to form secondary structures that help to select the correct 3' SS (e.g., in VMA10 and COF1) (Fig. 5F; Supplemental Fig. S4H-K; Gahura et al. 2011; Meyer et al. 2011). We propose that Brr2p facilitates splicing by promoting correct 3' SS positioning, particularly when this depends on the formation of a secondary structure and/or requires bridging of long BP-to-3' SS distances. This function is specifically deficient in the presence of Brr2-G858Rp. Notably, the brr2-G858R allele (originally termed rss1-1), was identified as a suppressor of a second-step splicing defect caused by insertion of a stable secondary structure immediately downstream from the $3^{\prime}$ SS in a reporter that already required an upstream secondary structure to mask a cryptic 3' SS (Lin and Rossi 1996). We now speculate that suppression resulted from an altered secondary structure around the 3' SS.

Brr2p might either impede formation of an unfavorable secondary structure in IL-E2 or promote formation of appropriate secondary structures, depending on the length and sequence of the BP-to-3' SS region. The exonic sequences that flank introns are not conserved, and their interactions with U5 loop 1 are stabilized by proteins, including Prp18p and Slu7p (Bacikova and Horovitz 2002; Aronova et al. 2007). These proteins are dispensable for in vitro splicing if the BP-to-3' SS distance is short and therefore independent of the secondary structure (Brys and Schwer 1996; Zhang and Schwer 1997). Significantly, brr2-G858R shows sl interactions with mutant alleles of U5 loop 1, PRP18, and SLU7 (Fig. 4A,B; Supplemental Table S2), all of which adversely affect exon positioning and progression through the second step (Bacikova and Horovitz 2002; Aronova et al. 2007 and references therein). Brr2p was previously suggested to be the receptor for Slu7p (van Nues and Beggs 2001), which then likely recruits Prp18p (James et al. 2002). Thus, by promoting the recruitment and integration of these factors into spliceosomes, Brr2p could drive exon interactions with U5 loop 1, stabilizing appropriate secondary structures and holding exons in a conformation favorable for step 2. Inefficient $3^{\prime}$ SS positioning in brr2-G858R cells could explain the persistence of the normally transient open conformation in the transition between the first and second steps (see above, Fig. 7C). Together with the RNAseq data, these results provide evidence for a previously unsuspected function for Brr2p in driving conformational rearrangements that lead to competence for the second step of splicing, especially with introns that have complex secondary structures.

During spliceosome activation, Prp8p and Snu114p are thought to control Brr2p function (Kuhn et al. 1999; Small et al. 2006). Conceivably, Brr2p might also function in collaboration with these proteins between the catalytic phases. In support of this, human Snul14 was crosslinked to structured regions between the BP and 3' SS in vitro (Liu et al. 1997). Also, Prp8p was cross-linked to the BP and 3' SS regions after the first step of splicing in vitro (Newman et al. 1995; Teigelkamp et al. 1995), and different prp 8 mutant alleles were shown to modulate the transition between the catalytic steps (Liu et al. 2007).

At present, it remains unclear whether the ATP-dependent helicase activity of Brr2p is required to promote the first-to-second-step transition. The G858R substitution is not predicted to impair the ATPase activity of Brr2p. Indeed, as brr2-G858R does not block splicing prior to the first step (Fig. 3D; Supplemental Fig. S3A), the ATPdependent activity required for U4/U6 unwinding is apparently not limiting, whereas the second step is. Notably, Prp22p, another spliceosomal RNA helicase, has an ATPase-independent function that was suggested to involve "organizing" the conformation of 3' ends of introns (Schwer and Gross 1998).

Gly858 is located in the putative strand separator hairpin (HP) loop of the $\mathrm{N}$-terminal helicase domain of 
Brr2p (Pena et al. 2009; Hahn and Beggs 2010; Cordin et al. 2012). Deletion or replacement of the HP is lethal, and it was proposed to act as a "cutting tool" that contributes to separating base-paired RNA strands when one strand of the RNA substrate is pulled $3^{\prime}$ to $5^{\prime}$ by the ratchet helix (Pena et al. 2009; Zhang et al. 2009). In DEAH-box helicases, the analogous structure (often referred to as the $5^{\prime} \mathrm{HP}$ ) acts together with other structural features to control access of RNA to the binding groove (He et al. 2010; Walbott et al. 2010). We speculate that the defective HP in Brr2-G858Rp might lead to unrestrained RNA access. This could prolong Brr2p-RNA interactions, interfering with the formation of the correct secondary structure and 3' SS positioning.

We conclude that in vivo cross-linking and sequencing approaches allow detection of molecular defects and transient conformations in the highly dynamic spliceosome. The analysis of transient events in the catalytic center during $3^{\prime}$ SS positioning may facilitate understanding of alternative $3^{\prime}$ SS usage in higher organisms, especially as the factors involved are highly conserved.

\section{Materials and methods}

Yeast strains and plasmids

See the Supplemental Material for details of plasmid and yeast strain construction; plasmids are listed in Supplemental Table S4.

\section{Plasmid shuffle and growth assays}

Cultivation of yeast cells on medium containing 5-fluoorotic acid (5FOA) allowed curing URA3-marked plasmids and complementation testing (plasmid shuffle). For growth assays, 5FOAselected transformants were grown in YPD $(2 \%[\mathrm{w} / \mathrm{v}]$ glucose), YPG (2\% [w/v] galactose), or SD medium supplemented with $2 \%$ $(\mathrm{w} / \mathrm{v})$ glucose or galactose. Cultures were serially diluted and spotted to the appropriate medium.

\section{CRAC}

Yeast strains expressing HTP-tagged proteins or protein fragments were grown in SD medium $(2 \%[\mathrm{w} / \mathrm{v}]$ glucose, supplemented with the appropriate amino acids) at $30^{\circ} \mathrm{C}, 25^{\circ} \mathrm{C}$, or $37^{\circ} \mathrm{C}$ $\left(37^{\circ} \mathrm{C}\right.$ shift for $\left.1 \mathrm{~h}\right)$ to $\mathrm{OD}_{600} 0.5$ before UV irradiation in growth medium using the Megatron, as described (Granneman et al. 2011). The CRAC technique was performed essentially as described (Granneman et al. 2009), except that cell extract preparation included high-speed centrifugation $440,000 \mathrm{~g}$ for $1 \mathrm{~h}$ at $4^{\circ} \mathrm{C}$ ). Sequencing libraries were generated using the $5^{\prime}$ Solexa or barcoded 5' and miRCAT-33 adaptors (Supplemental Table S5). Bioinformatics procedures used for sequence analyses are described in the Supplemental Material.

\section{Primer extension}

Yeast cultures were harvested at the indicated times after shift to $37^{\circ} \mathrm{C}$ or to glucose-containing medium, and RNA was extracted. Primers U3-E2 (5'-CCAAGTTGGATTCAGTGGCTC-3') or ACT1-CUP1 (5'-GGCACTCATGACCTTC-3') were ${ }^{32} \mathrm{P}-1 \mathrm{a}-$ beled and used for reverse transcription of 2-4 $\mu \mathrm{g}$ of total RNA. Products were analyzed on $7 \%(\mathrm{w} / \mathrm{v})$ PAA gels.
EMSA

Varying amounts $(0-500 \mathrm{nM})$ of purified yeast Brr2 protein (Supplemental Material) were combined with $10 \mathrm{nM}^{32} \mathrm{P}$-labeled wild-type or mutant U4/U6 snRNA duplex (Supplemental Material) in RNA-binding buffer (10 mM HEPES at pH 7.5, $1 \mathrm{mM}$ $\mathrm{MgCl}_{2}, 100 \mathrm{mM} \mathrm{NaCl}, 5 \%$ glycerol) and incubated for $30 \mathrm{~min}$ on ice. Ficoll 400 was added to a final concentration of $1 \%(\mathrm{v} / \mathrm{v})$, and samples were subjected to native PAGE $(6 \%[\mathrm{w} / \mathrm{v}] 0.5 \times \mathrm{TBE})$.

\section{RNA-seq}

Yeast cultures were grown $\left(25^{\circ} \mathrm{C}, \mathrm{YPD}\right)$ to $\mathrm{OD}_{600} 0.5$ and harvested. RNA was extracted and DNase-treated (Ambion). RNA was poly $(\mathrm{A})^{+}$-selected and reverse-transcribed by random priming. Sequencing libraries were generated using barcoded adapters (Supplemental Table S5) and then pooled and jointly sequenced with 75-nt paired-end reads (Illumina). Bioinformatics procedures used for sequence analyses are described in the Supplemental Material.

\section{Acknowledgments}

We thank O. Cordin and S. Granneman for helpful discussions and advice on experimental procedures, and O. Cordin for providing anti-Brr2p antibodies. We are grateful to I. Turner and A.J. Newman for communicating where BRR2 can be split without loss of function, and to R. O'Keefe and C. Maeder for sharing plasmids and strains. D.H. was supported by the Darwin Trust of Edinburgh and by Wellcome Trust grant 087551 to J.D.B., G.K. was supported by an EMBO LTF and the Wellcome Trust, D.T. is supported by the Wellcome Trust, and J.D.B. is the Royal Society Darwin Trust Research Professor. The Wellcome Trust Centre for Cell Biology is supported by Wellcome Trust core funding (092076).

\section{References}

Aronova A, Bacikova D, Crotti LB, Horovitz DS, Schwer B. 2007. Functional interactions between Prp8, Slu7, and U5 snRNA during the second step of pre-mRNA splicing. RNA 13: 1437-1444.

Bacikova D, Horovitz DS. 2002. Mutational analysis identifies two separable roles of the Saccharomyces cerevisiae splicing factor Prp18. RNA 8: 1280-1293.

Bacikova D, Horovitz DS. 2005. Genetic and functional interaction of evolutionarily conserved regions of the Prp18 protein and the U5 snRNA. Mol Cell Biol 25: 2107-2116.

Bessonov S, Anokhina M, Will C, Urlaub H, Luehrmann R. 2008. Isolation of an active step I spliceosome and composition of its RNP core. Nature 452: 846-850.

Brow DA, Guthrie C. 1988. The spliceosomal RNA U6 is remarkably conserved from yeast to mammals. Nature 334: 213-218.

Brys A, Schwer B. 1996. Requirement for SLU7 in yeast premRNA splicing is dictated by the distance between the branchpoint and the 3' splice site. RNA 2: 707-717.

Cordin O, Hahn D, Beggs JD. 2012. Structure, function and regulation of spliceosomal RNA helicases. Curr Opin Cell Biol 24: 1-8.

Crotti LB, Bacikova D, Horovitz DS. 2007. The Prp18 protein stabilizes the interaction of both exons with the U5 snRNA during the second step of pre-mRNA splicing. Genes Dev 21: 1204-1216.

Frilander MJ, Steitz JA. 2001. Dynamic exchanges of RNA interactions leading to catalytic core formation in the U12dependent spliceosome. Mol Cell 7: 217-226. 
Gahura O, Hammann C, Valentova A, Puta F, Folk P. 2011. Secondary structure is required for $3^{\prime}$ splice site recognition in yeast. Nucleic Acids Res 39: 9759-9767.

Granneman S, Kudla G, Petfalski E, Tollervey D. 2009. Identification of protein binding sites on U3 snoRNA and prerRNA by UV cross-linking and high-throughput analysis of cDNAs. Proc Natl Acad Sci 106: 9613-9618.

Granneman S, Petfalski E, Tollervey D. 2011. A cluster of ribosome synthesis factors regulate pre-rRNA folding and 5.8S rRNA maturation by the Ratl exonuclease. EMBO I 30: 4006-4019.

Häcker I, Sander B, Golas MM, Wolf E, Karagöz E, Kastner B, Stark H, Fabrizio P, Lührmann R. 2008. Localization of Prp8, Brr2, Snu114 and U4/U6 proteins in the yeast tri-snRNP by electron microscopy. Nat Struct Biol 15: 1206-1212.

Hahn D, Beggs JD. 2010. Brr2p RNA helicase with a split personality: Insights into structure and function. Biochem Soc Trans 38: 1105-1109.

Hayduk AJ, Stark M, Rader SD. 2012. In vitro reconstitution of yeast splicing with U4 snRNA reveals multiple roles for the 3' stem-loop. RNA 18: 1075-1090.

He Y, Andersen GR, Nielsen KH. 2010. Structural basis for the function of DEAH helicases. EMBO Rep 11: 180-186.

James S-A, Turner W, Schwer B. 2002. How Slu7 and Prp18 cooperate in the second step of yeast pre-mRNA splicing. RNA 8: 1068-1077.

Kim H-D, Rossi J. 1999. The first ATPase domain of the yeast $246-\mathrm{kDa}$ protein is required for in vivo unwinding of the U4/ U6 duplex. RNA 5: 959-971.

Konarska MM, Vilardell J, Query CC. 2006. Repositioning of the reaction Intermediate within the catalytic center of the spliceosome. Mol Cell 21: 543-553.

Kudla G, Granneman S, Hahn D, Beggs JD, Tollervey D. 2011. Cross-linking, ligation, and sequencing of hybrids reveals RNA-RNA interactions in yeast. Proc Natl Acad Sci 108: 10010-10015.

Kuhn AN, Li ZR, Brow DA. 1999. Splicing factor Prp8 governs U4/U6 RNA unwinding during activation of the spliceosome. Mol Cell 3: 65-75.

Laggerbauer B, Achsel T, Luhrmann R. 1998. The human U5200kD DEXH-box protein unwinds U4/U6 RNA duplices in vitro. Proc Natl Acad Sci 95: 4188-4192.

Lauber J, Fabrizio P, Teigelkamp S, Lane WS, Hartmann E, Lührmann R. 1996. The HeLa 200 kDa U5 snRNP-specific protein and its homologue in Saccharomyces cerevisiae are members of the DEXH-box protein family of putative RNA helicases. EMBO I 15: 4001-4015.

Lescoute A, Westhof E. 2006. Topology of three-way junctions in folded RNAs. RNA 12: 83-93.

Lesser CF, Guthrie C. 1993. Mutational analysis of pre-mRNA splicing in S. cerevisiae using a sensitive new reporter gene, CUP1. Genetics 133: 851-863.

Lin J, Rossi J. 1996. Identification and characterization of yeast mutants that overcome an experimentally introduced block to splicing at the $3^{\prime}$ splice site. RNA 2: 835-848.

Liu Z-R, Laggerbauer B, Lührmann R, Smith CWJ. 1997. Crosslinking of the U5 snRNP-specific $166-\mathrm{kDa}$ protein to RNA hairpins that block step 2 of splicing. RNA 3: 1207-1219.

Liu S, Rauhut R, Vornlocher H-P, Lührmann R. 2006. The network of protein-protein interactions within the human U4/U6.U5 tri-snRNP. RNA 12: 1418-1430.

Liu L, Query CC, Konarska MM. 2007. Opposing classes of prp8 alleles modulate the transition between the catalytic steps of pre-mRNA splicing. Nat Struct Biol 14: 519-526.

McPheeters DS. 1996. Interactions of the yeast U6 snRNA with the pre-mRNA branch site. RNA 2: 1110-1123.
Mefford MA, Staley JP. 2009. Evidence that U2/U6 helix I promotes both catalytic steps of pre-mRNA splicing and rearranges in between these steps. RNA 15: 1386-1397.

Meyer M, Plass M, Pérez-Valle J, Eyras E, Vilardell J. 2011. Deciphering 3'ss selection in the yeast genome reveals an RNA thermosensor that mediates alternative splicing. Mol Cell 43: 1033-1039.

Mozaffari-Jovin S, Santos KF, Hsiao H-H, Will CL, Urlaub H, Wahl MC, Lührmann R. 2012. The Prp8 RNase H-like domain inhibits Brr2-mediated U4/U6 snRNA unwinding by blocking Brr2 loading onto the U4 snRNA. Genes Dev (this issue). doi: 10.1101/gad.200949.112.

Newman AJ. 1997. The role of U5 snRNP in pre-mRNA splicing. EMBO J 16: 5797-5800.

Newman AJ, Teigelkamp S, Beggs JD. 1995. snRNA interactions at $5^{\prime}$ and $3^{\prime}$ splice sites monitored by photoactivated crosslinking in yeast spliceosomes. RNA 1: 968-980.

Noble SM, Guthrie C. 1996. Identification of novel genes required for yeast pre-mRNA splicing by means of coldsensitive mutations. Genetics 143: 67-80.

Nottrott S, Urlaub H, Lührmann R. 2002. Hierarchical, clustered protein interactions with U4/U6 snRNA: A biochemical role for U4/U6 proteins. EMBO J 12: 5527-5538.

O'Keefe RT, Norman CM, Newman AJ. 1996. The invariant U5 snRNA loop1 sequence is dispensable for the first catalytic step of pre-mRNA splicing in yeast. Cell 86: 679689.

Pena V, Mozaffari Jovin S, Fabrizio P, Orlowski J, Bujnicki JM, Lührmann R, Wahl MC. 2009. Common design principles in the spliceosomal RNA helicase Brr2 and in the Hel308 DNA helicase. Mol Cell 35: 454-466.

Query CC, Konarska MM. 2004. Suppression of multiple substrate mutations by spliceosomal prp8 alleles suggests functional correlations with ribosomal ambiguity mutants. Mol Cell 14: 343-354.

Raghunathan PL, Guthrie C. 1998. RNA unwinding in U4/U6 snRNPs requires ATP hydrolysis and the DEIH-box splicing factor Brr2. Curr Biol 8: 847-855.

Rasche N, Dybkov O, Schmitzova J, Akyildiz B, Fabrizio P, Luehrmann R. 2012. Cwc2 and its human homolouge RBM22 promote an active conformation of the spliceosome catalytic centre. EMBO I 31: 1591-1604.

Schwer B, Gross CH. 1998. Prp22, a DExH-box RNA helicase, plays two distinct roles in yeast pre-mRNA splicing. $E M B O J$ 17: 2086-2094.

Schwer B, Guthrie C. 1992. A conformational rearrangement in the splicosome is dependent on PRP16 and ATP hydrolysis. EMBO J 11: 5033-5039.

Small EC, Leggett SR, Winans AA, Staley JP. 2006. The EFG-like GTPase Snu114p regulates spliceosome dynamics mediated by Brr2p, a DExD/H Box ATPase. Mol Cell 23: 389-399.

Smith DJ, Query CC, Konarska MM. 2008. 'Nought may endure but mutability': Spliceosome dynamics and the regulation of splicing. Mol Cell 30: 657-666.

Staley JP, Guthrie C. 1999. An RNA switch at the $5^{\prime}$ splice site requires ATP and the DEAD box protein Prp28. Mol Cell 3: 55-64.

Teigelkamp S, Newman AJ, Beggs JD. 1995. Extensive interactions of PRP8 protein with the $5^{\prime}$ and $3^{\prime}$ splice sites during splicing suggest a role in stabilization of exon alignment by U5 snRNA. EMBO J 14: 2602-2612.

Valdakhan S. 2007. The spliceosome: Caught in a web of shifting interactions. Curr Opin Struct Biol 17: 310-315.

van Nues R, Beggs JD. 2001. Functional contacts with a range of splicing proteins suggest a central role for Brr2p in the 
dynamic control of the order of events in spliceosomes of Saccharomyces cerevisiae. Genetics 157: 1457-1467.

Walbott H, Mouffok S, Capeyrou R, Lebaron S, Humbert O, van Tilbeurgh H, Henry Y, Leulliot N. 2010. Prp43p contains a processive helicase structural architecture with a specific regulatory domain. EMBO J 29: 2194-2204.

Will C, Luehrmann R. 2011. Spliceosome structure and function. Cold Spring Harb Perspect Biol 3: a003707. doi: 10.1101/ cshperspect.a003707.

Xu D, Friesen JD. 2000. Splicing factor Slt11p and its involvement in formation of U2/U6 Helix II in activation of the yeast spliceosome. Mol Cell Biol 21: 1011-1023.

Zhang X, Schwer B. 1997. Functional and physical interaction between the yeast splicing factors Slu7 and Prp18. Nucleic Acids Res 25: 2146-2152.

Zhang L, Xu T, Maeder C, Bud L-O, Shanks J, Nix J, Guthrie C, Pleiss JA, Zhao R. 2009. Structural evidence for consecutive Hel308-like modules in the spliceosomal ATPase Brr2. Nat Struct Biol 16: 731-739. 


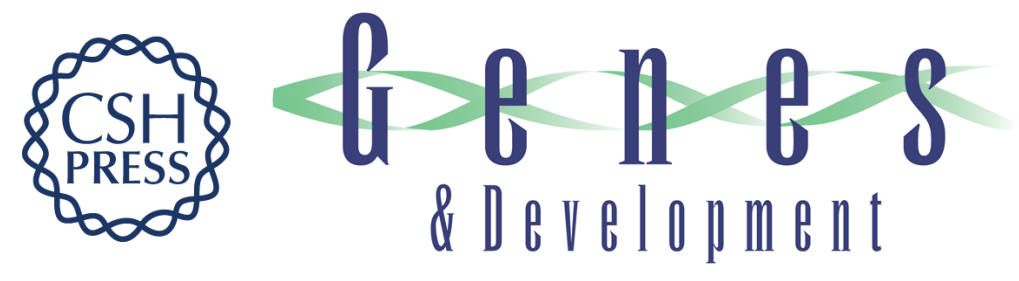

\section{Brr2p-mediated conformational rearrangements in the spliceosome during activation and substrate repositioning}

Daniela Hahn, Grzegorz Kudla, David Tollervey, et al.

Genes Dev. 2012, 26:

Access the most recent version at doi:10.1101/gad.199307.112

\section{Supplemental http://genesdev.cshlp.org/content/suppl/2012/10/25/26.21.2408.DC1 \\ Material}

Related Content The Prp8 RNase H-like domain inhibits Brr2-mediated U4/U6 snRNA unwinding by blocking Brr2 loading onto the U4 snRNA

Sina Mozaffari-Jovin, Karine F. Santos, He-Hsuan Hsiao, et al.

Genes Dev. November, 2012 26: 2422-2434 Spliceosome activation: U4 is the path, stem I is the goal, and Prp8 is the keeper. Let's cheer for the ATPase Brr2!

Klaus $\mathrm{H}$. Nielsen and Jonathan P. Staley

Genes Dev. November , 2012 26: 2461-2467

References This article cites 54 articles, 22 of which can be accessed free at:

http://genesdev.cshlp.org/content/26/21/2408.full.html\#ref-list-1

Articles cited in:

http://genesdev.cshlp.org/content/26/21/2408.full.html\#related-urls

License Freely available online through the Genes \& Development Open Access option.

Email Alerting Receive free email alerts when new articles cite this article - sign up in the box at the top Service right corner of the article or click here.

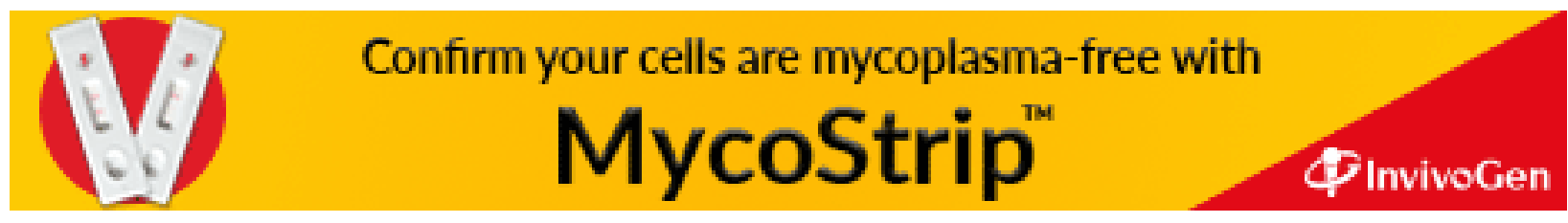

